\title{
Pharmaceutical Patent Analyst: a look back on the year
}

\author{
Harriet Wall*,1 \\ ${ }^{1}$ Future Science Group, Unitec House, 2 Albert Place, London, N3 1QB, UK \\ *Author for correspondence: h.wall@future-science.com
}

First draft submitted: 25 November 2019; Accepted for publication: 25 November 2019; Published

online: 3 January 2020

Keywords: pharmaceutical patent analyst • top content

Welcome to the final issue of volume 8 of Pharmaceutical Patent Analyst! In this Foreword we will discuss some of the highlights that the journal has seen over the last year as well as what there is to expect in 2020. We are grateful to our authors, editorial board members, peer reviewers and readers - we look forward to continuing to work with all of our contributors again in 2020.

\section{Content highlights for 2019}

Our ongoing series of Patent Highlights has once again proved popular over the year. In these articles, Herman Mucke has provided an up to date snapshot of recent noteworthy developments in patent literature with relevance to pharmaceutical and medicinal research and development [1-5].

One of our most read articles of the year was 'International collaboration generates high quality clusters of pharmaceutical patents' [6]. In this Review, Christian Moser, Swiss Federal Institute of Intellectual Property (Bern, Switzerland), provided an overview of the current pharmaceutical patent landscape with respect to its qualitative aspects, concluding that patents originating from international collaborations generally yield a higher impact when compared with one-sided publications.

In addition to this, Richard A Cerione, Cornell University (NY, USA), provided a popular article concerning the current patent landscape of the inhibition of cancer metabolism [7]. In this Patent Review, the authors give an overview of small-molecule inhibitors which target cancer progression - with a focus on inhibitors of glycolysis, anaplerosis, the tricarboxylic acid cycle and nutrient import - along with their associated patents.

As well as our core content of Reviews, the journal has also featured content on topical areas of debate relevant to academia and important issues related to IP law; including Editorials, Commentaries, Interviews and more. Of interest is 'Current patent and clinical status of stimulator of interferon genes (STING) agonists for cancer immunotherapy' [8]. In this Editorial, Gills Berger, Harvard Medical School (MA, USA), discussed the patent landscape of nucleotide and nonnucleotide STING agonists and their significance in cancer immunotherapy.

Further, Paul A Ragusa, Baker Botts LLP (NY, USA), notably compared the differences between post grant review and inter partes review in the Editorial entitled 'Opposing a granted patent in the USA: post grant and inter partes review' $[9]$.

Additionally, this current issue (0806) of Pharmaceutical Patent Analyst features an interview [10] with Sang Min Lim, Korea Institute of Science and Technology (Seoul, Korea), who discusses their recent patent review entitled 'Development of tau-directed small-molecule modulators for Alzheimer's disease: a recent patent review (2014-2018)' [11].

\section{Demographics}

Pharmaceutical Patent Analyst continues to reach experts from all over the world. Over the past year, the majority of our readership originated from North America, followed by Asia and Europe (Figure 1).

Interestingly, the authorship of our content differed slightly from the journal's readership - with a relatively even contribution from Europe, North America and Asia (Figure 2). 


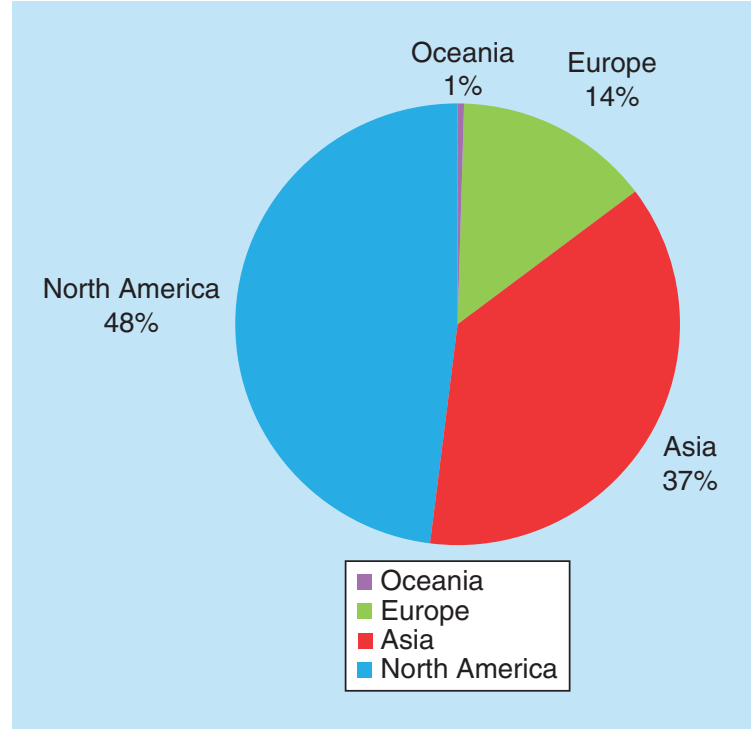

Figure 1. Percentage readership by geographic location.

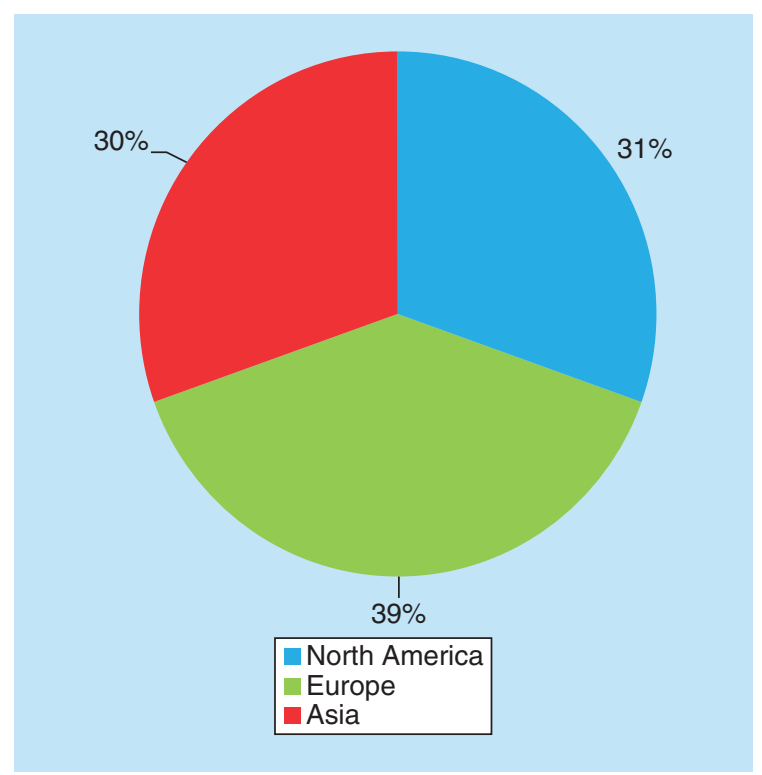

Figure 2. Percentage authorship by geographical location.

\section{Article outreach \& online presence}

Pharmaceutical Patent Analyst continues to be active across social media and we are keen for you to engage. Follow us on Twitter at @fsgppa [12] to stay updated with our latest content - including our journal highlights and the latest patent news.

We also recommend you to get involved through our partnered digital site, RxNet [13], which provides a free interactive resource for you to engage with. RxNet covers up-to-date news, views and research on the entire drug discovery pipeline. The site posts regular updates on developments in drug discovery, including exclusive content from the authors of Pharmaceutical Patent Analyst.

\section{Conclusion}

We appreciate the support and engagement that has been provided over the past year, and look forward to what is to come in 2020. As always, we are happy for you to submit any unsolicited articles to the journal - whether they are patent reviews, spotlights and opinion pieces. If you have a submission that you would like us to consider, you can find details on article preparation or submission online [14] or get in touch. 
Finally, we would like to thank everyone for their continued feedback and support - we look forward to working with all of you over the coming year.

Financial \& competing interests disclosure

$\mathrm{H}$ Wall is an employee of Future Science Ltd. The author has no other relevant affiliations or financial involvement with any organization or entity with a financial interest in or financial conflict with the subject matter or materials discussed in the manuscript apart from those disclosed.

No writing assistance was utilized in the production of this manuscript.

\section{References}

1. Mucke HAM. Patent highlights August-September 2018. Pharm. Pat. Anal. 8(1), 7-17 (2019).

2. Mucke HAM. Patent highlights October-November 2018. Pharm. Pat. Anal. 8(2), 43-50 (2019).

3. Mucke HAM. Patent highlights December 2018-January 2019. Pharm. Pat. Anal. 8(3), 73-80 (2019).

4. Mucke HAM. Patent highlights February-March 2019. Pharm. Pat. Anal. 8(4), 109-116 (2019).

5. Mucke HAM. Patent highlights April-May 2019. Pharm. Pat. Anal. 8(5), 165-173 (2019).

6. Moser C, Villa AM, Mueller H. International collaboration generates high quality clusters of pharmaceutical patents. Pharm. Pat. Anal. 8(5), 193-202 (2019).

7. Katt WP, Cerione RA. Inhibition of cancer metabolism: a patent landscape. Pharm. Pat. Anal. 8(4), 117-138 (2019).

8. Marloye M, Lawler SE, Berger G. Current patent and clinical status of stimulator of interferon genes (STING) agonists for cancer immunotherapy. Pharm. Pat. Anal. 8(4), 87-90 (2019).

9. Ragusa PA, Zhang Z. Opposing a granted patent in the USA: post grant and inter partes review. Pharm. Pat. Anal. 8(3), 61-63 (2019).

10. Lim SM. The recent pharmaceutical patent landscape for Alzheimer's disease: an interview with Sang Min Lim. Pharm. Pat. Anal. 8(6), 215-216 (2019).

11. Lee HE, Lim D, Lee JY, Lim SM, Pae AN. Development of tau-directed small molecule modulators for Alzheimer's disease: a recent patent review (2014-2018). Pharm. Pat. Anal. 8(1), 15-39 (2019).

12. Pharmaceutical Patent Analyst, Twitter page. https://twitter.com/fsgppa

13. Rx Net. https://www.rx-network.com/

14. Pharmaceutical Patent Analyst. www.future-science.com/journal/ppa 
